\title{
Prácticas endogámicas en la Costa Onubense. Matrimonio y Consanguinidad en Ayamonte en el Siglo XVIII http://dx.doi.org/10.33776//hh.v15i0.5286
}

\author{
María A. Márquez Gento \\ Petra Márquez Gento \\ UNIVERSIDAD DE HUELVA \\ petra-m-g@hotmail.com
}

Fecha de recepción: 24/02/2021

Fecha de aceptación: 1/03/2021

\section{Resumen}

El objetivo principal consiste en analizar los enlaces matrimoniales contraídos entre individuos que poseen algún vínculo de parentesco entre ellos, concretamente el de consanguinidad. Analizaremos el porqué de estos enlaces endogámicos y la posición de la Iglesia ante este tipo de uniones. Las fuentes utilizadas son el Archivo Diocesano y los expedientes del Libro de matrimonios, por lo tanto, se trata de una metodología de tipo histórica, basada en la investigación archivística. La endogamia matrimonial contribuía a configurar grupos de parentesco bastante densos, en los que los parientes de una familia eran generalmente parientes entre sí, hallándose ligados muchas veces por parentescos múltiples. La prohibición de estos enlaces matrimoniales entre consanguíneos por la Iglesia se basó en tres argumentos: una razón eugenesica, la difusión de la caridad y la protección de la familia. En líneas generales, los datos obtenidos indican que la endogamia familiar en Ayamonte no fue una práctica muy arraigada pero sí una costumbre practicada por una parte de su sociedad.

\section{Palabras clave}

Endogamia; matrimonio; iglesia; Ayamonte; consanguinidad; dispensa

\section{Abstract}

The main objective is to analyze the marital bonds contracted between individuals who have a relationship between them, specifically that of consanguinity. We will analyze the reason these inbreeding links and the position of the Church in this kind of unions. The sources used are the Diocesan Archive and the files of the Book of Marriages, therefore, it is a historical methodology, based on archival research. Marriage inbreeding helped to set up fairly dense kinship groups, in which the relatives of a family were generally relatives to each other, being often linked by multiple kinships. The prohibition of these marital links between consanguines by the Church was based on three arguments: a eugenic reason, the dissemination of charity and the protection of the family. In general, the data obtained indicate that family inbreeding in Ayamonte was not a deep-rooted practice but a custom practiced by a part of their society.

\section{KEY WORDS}

Inbreeding; marriage; church; Ayamonte; consanguinity; dispensation. 


\section{Glosario}

A continuación, definiremos una serie de términos que trataremos con cierta regularidad a lo largo de las líneas precedentes; para ello, nos basaremos en los autores Godoy (1986) y Molinié Bertrand (2000).

- Afinidad: Relación entre parientes políticos.

- Agnado: Pariente por línea exclusivamente masculina.

- Cognado: Pariente por línea masculina o femenina.

- Clan: Grupo extenso de descendencia unilineal en el que las relaciones más extensas de parentesco no se calcula a través de una genealogía.

- Consanguinidad: Entendemos por ello al conjunto de relaciones afectivo-sexuales existente entre dos persona unidas por un vínculo sanguíneo, procedente por generación carnal unas de otras o ambas desde un tronco común.

- Compadrazgo: Forma de parentesco espiritual que une a los padres y a los padrinos de sus hijos.

- Dispensas de matrimonio: Las solicitudes de dispensa de los grados de parentesco de consanguinidad y afinidad, corresponden a los impedimentos o prohibiciones que la Iglesia establece, bien para reducir o controlar la endogamia o para evitar casos de poligamia. Es el Papa, mediante Bula, o el Obispo el que otorga dichas dispensas.

Este documento se acoge a una fórmula estándar, que contiene las declaraciones de los contrayentes que la solicitan y de varios testigos de su entorno (de información general o de oficio), para esclarecer la edad de los cónyuges, su estado civil, profesión, sus ascendientes y lazos de consanguinidad o afinidad... Una vez estudiados dichos elementos, si no existe ninguna contrariedad se procederá a emitir la dispensa que les posibilitará contraer matrimonio.

- Endogamia: Norma que exige el matrimonio dentro del grupo al que se pertenece.

- Familia: Según el Diccionario de la Real Academia de la Lengua Española, 8 de las 10 acepciones $^{1}$

(Del lat. familia).

1. f. Grupo de personas emparentadas entre sí que viven juntas.

2. f. Conjunto de ascendientes, descendientes, colaterales y afines de un linaje.

3. f. Hijos o descendencia.

4. f. Conjunto de personas que tienen alguna condición, opinión o tendencia común.

5. f. Conjunto de objetos que presentan características comunes.

6. f. Número de criados de alguien, aunque no vivan dentro de su casa.

7. f. Cuerpo de una orden o religión, o parte considerable de ella.

8. f. coloq. Grupo numeroso de personas.

- Grado: Dentro de los impedimentos establecidos por la iglesia para que dos individuos no puedan contraer matrimonio se encuentran los impedimentos de parentesco por consanguinidad o afinidad. Como medida para establecer el parentesco existente entre las parientes se establecen los grados, que indican mayor o menor proximidad

1 http://www.rae.es 22 edición. 
(primer grado, segundo grado...) Existen dos formas de computar esos grados, el sistema romano y el germánico. El sistema germánico emplea un cómputo de la línea colateral. El parentesco en esta línea se medía subiendo hasta el tronco común por una sola línea, y si se trataba de líneas desiguales, por la más larga, pero teniendo en cuenta el grado de la otra. Así, entre tío y sobrino había parentesco de segundo grado mezclado con primero. En el sistema romano, los grados son tantos cuantas son las personas de ambas líneas, descontado el tronco: por tanto tío y sobrino son parientes consanguíneos en tercer grado.

Durante el periodo que nos ocupa, la prohibición se extendía hasta el cuarto grado, quedando graduado los grados consanguíneos del siguiente modo.

Segundo grado: primo hermano

Tercer grado: primo segundo.

Tercer con cuarto grado: tio o tía con sobrino o sobrina o primo o prima segundo del padre o madre.

Cuarto grado: primos terceros.

- Línea: Consiste en la serie ordenada de personas procedentes de un mismo tronco próximo, que descienden inmediata o mediatamente unos de otros, es decir, serie de personas que descienden unas de otras de manera sucesiva. Se divide en línea recta o línea colateral. La línea recta puede ser ascendente (orden de sucesión hacia los padres, abuelos y así sucesivamente) o descendente (orden de sucesión de los hijos, nietos y parientes sucesivos). En la línea colateral, los parientes proceden de una misma raíz común, pero entre ellos ninguno desciende uno del otro, pudiendo ser también ascendente o descendente.

- Levítico: Según la Biblia (1964), es el cuerpo dogmático sobre lo que la institución eclesiástica asienta su prohibición de mantener relaciones entre consanguíneos. Se trata del cuarto capítulo del Antiguo Testamento. Es una compilación de textos legislativos de diferentes épocas que recogen los derechos y deberes de la tribu de Leví. Se supone que la fusión de estos diversos cuerpos legislativos tuvo lugar en el siglo $\mathrm{V}$ a. C. La idea teológica central es la santidad de Dios que ha de ser comunicada al pueblo de Israel, particularmente a los sacerdotes.

El tema que nos ocupa reside en la Cuarta Parte denominada Código de Santidad (Capítulo 17-27). Nos remitimos al capítulo 18: "Unciones ilícitas y pecados contra naturaleza”, versículos 6-18.

6. Ninguno de vosotros se acercará a una consanguínea suya para descubrir su desnudez. Yo, Yavé.

7. No descubrirás la desnudez de tu padre ni la de tu madre; es tu madre; no descubrirás su desnudez.

8. No descubrirás la desnudez de la mujer de tu padre; es la desnudez de tu padre.

9. No descubrirás la desnudez de tu hermana, hija de tu padre o hija de tu madre; nacida en la casa o nacida fuera de ella, no descubrirás su desnudez.

10. No descubrirás la desnudez de la hija de tu hijo o de la hija de tu hija, porque es tu propia desnudez.

11. No descubrirás la desnudez de la hija de la mujer de tu padre, nacida de tu padre, es tu hermana. 
12. No descubrirás la desnudez de la hermana de tu padre; es la carne de tu padre.

13. No descubrirás la desnudez de la hermana de tu madre; es la carne de tu madre.

14. No descubrirás la desnudez del hermano de tu padre acercándote a su mujer; es tu tía.

15. No descubrirás la desnudez de tu nuera; es la mujer de tu hijo; no descubrirás su desnudez.

16. No descubrirás la desnudez de la mujer de tu hermano; es la desnudez de tu hermano.

17. No descubrirás la desnudez de una mujer y la de su hija, ni tomarás a la hija de su hijo, ni a la hija de su hija para descubrir su desnudez; son parientes; es un crimen.

18. No tomarás a la hermana de tu mujer para hacer de ella una rival suya descubriendo su desnudez con la de tu mujer en vida de ésta.

- Levirato: Obligación del hermano del marido fallecido de casarse con la viuda para dar descendencia al nombre del difunto.

- Linaje: Grupo de descendencia unilateral ramificado en el que los vínculos se determinan genealógicamente.

- Matrimonio: Diccionario de la Real Academia de la Lengua Española, 3 de las 4 acepciones. $^{2}$

(Del lat. matrimonium).

1. m. Unión de hombre y mujer concertada mediante determinados ritos o formalidades legales.

2. m. En el catolicismo, sacramento por el cual el hombre y la mujer se ligan perpetuamente con arreglo a las prescripciones de la Iglesia.

3. m. coloq. Marido y mujer.

$\sim$ civil.

1. m. El que se contrae según la ley civil, sin intervención del párroco.

La Ley aprobada en 2005 por el Gobierno socialista de José Luis Rodríguez Zapatero, aprobó el matrimonio entre personas del mismo sexo en España. Siete años después de que se legalizaran las uniones entre homosexuales, la Real Academia de la Lengua ha incorporado, en su nueva versión online del Diccionario, esta acepción de la palabra matrimonio: "En determinadas legislaciones, unión de dos personas del mismo sexo, concertada mediante ciertos ritos o formalidades legales, para establecer y mantener una comunidad de vida e intereses", dice la nueva definición que se recogerá en la próxima edición impresa del diccionario de español, la número 23, la cual se publicó en 2014 y que se suma a la acepción habitual de unión entre un hombre y una mujer.

- Matrimonio: Juan Pablo II. Exhort. Ap. Familiaris consortio, n. 11: según cuenta Fornés (2008): "Pacto de amor conyugal o elección consciente y libre, con la que el hombre y la mujer aceptan la comunidad intima de vida y amor, querida por Dios mismo, que sólo bajo esta luz manifiesta su verdadero significado".

- Matrimonio: Constitución Española de 19783. Título I. De los derechos y deberes fundamentales. Capitulo segundo, sección segunda, De los derechos y deberes de los ciudadanos. Artículo 32.

2 http://www.rae.es, 22 edición.

3 La Constitución española de 1978. Anaya, 1982, pp. 239.

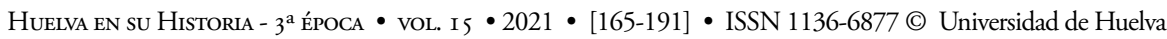


El hombre y la mujer tienen derecho a contraer matrimonio con plena igualdad jurídica.

La ley regulará las formas de matrimonio, la edad y capacidad para contraerlo, los derechos y deberes de los cónyuges, las causas de separación y sus efectos.

- Parentesco: Relación entre el prometido o prometida y un familiar consanguíneo de su pareja.

- Sororato: Obligación de la hermana de la esposa difunta de casarse con el viudo de su hermana.

- Tronco: Ascendiente común, más o menos cercano del cual desciende por generación carnal las personas consanguíneas entre sí. Consta de dos personas (varón y hembra) que en la consanguinidad plena será común a los hermanos y en la semiplena será común o el padre o la madre.

\section{INTRODUCCIÓN}

\subsection{OBJETIVOS}

Como objetivo principal se propone centrarnos en el estudio de la Historia de la familia y dar visibilidad a aquellos datos que evidencien las posibles relaciones endogámicas en el entorno familiar, y comprender las situaciones que crearon dichos enlaces. Nuestra línea de investigación pretende aportar algún dato significativo a la Historia de las Mentalidades o Historia Social.

Se pretende analizar los enlaces matrimoniales contraídos entre individuos que poseen algún vínculo de parentesco entre ellos, concretamente el de consanguinidad. Analizaremos el porqué de estos enlaces endogámicos, las causas que los motivaron, la posición de la Iglesia ante este tipo de uniones.

Las relaciones que vamos a contemplar en torno a la familia tenían una entidad estructural específica dentro del entramado social y político de la Espańa del Antiguo Régimen, a partir de los vínculos que articulaban las relaciones entre los hombres. La sociedad era contemplada como un agregado de cuerpos sociales y políticos a la vez (comunidades territoriales, estados señoriales, parroquias, corporaciones laborales y religiosas...) a los que hombres y mujeres se adscribían. A la vez, los distintos individuos estaban vinculados entre sí por lazos personales como los de familia, parentesco, amistad, vecindad, domesticidad, vasallaje, clientelismo... que vinculaban a las personas entre sí, creando fuertes vínculos afectivos y sociales, de manera más o menos permanente en el tiempo.

\subsection{FUENTES}

Archivo Diocesano de Huelva.

Dentro de este Archivo hemos consultado la sección Matrimonios apostólicos. Esta sección recoge las dispensas solicitadas a la Curia Romana para que se le dispensase el determinado grado de consanguinidad o afinidad. Constan tanto de la solicitud de la dispensa como de la Bula papal que se emitía una vez dispensado el grado, así como el Auto y la Penitencia pública que se imponía a los contrayentes. 
El Índice de matrimonios (documento descriptivo) de esta localidad dicta desde 1591 a 1877. Este índice, también llamado Libro de matrimonios únicamente recoge el nombre de los contrayentes y el año en que se solicitó o emitió la dispensa.

Existen 6 tomos para Ayamonte distribuidos de la siguiente manera:

Tomo 1 (Expedientes del 1-80)

Tomo 2 (Expedientes del 81-160)

Tomo 3 (Expedientes 161-192)

Tomo 4 (Expedientes del 193-220)

Tomo 5 (Expedientes del 221-280)

Tomo 6 (Expedientes de 281-326)

Salvo el primero, hemos consultado los cinco restantes.

\section{Fuentes bibliográficas}

La consulta de cuantiosos manuales y obras versadas sobre la Historia de la familia, nos ha reportado una visión global y precisa de la familia y del matrimonio en el periodo moderno.

Si hemos de citar una obra que ha servido de base para nuestra investigación sin lugar a duda es la del sevillano José Luis Sánchez Lora Demografía y Análisis Histórico. Ayamonte 1600-1860. Acompañando a ésta, como pilar esencial para cualquier investigador que se adentre en la Huelva del XVIII, se sitúa el completísimo manual de Francisco Nuñez Roldán, En los confines del reino. Huelva y su tierra en el siglo XVIII.

Los datos numéricos extraídos de ambas han sido elementales para construir varios capítulos que precisaban de estas cifras para conformarse históricamente.

Las demás obras, no por ello menos significativas, han conformado, cada una en sus lindes, el corpus teórico de nuestro trabajo.

\subsection{MÉTODO}

Se trata de una metodología de tipo histórica, basada en la investigación archivística. $\mathrm{Al}$ querer abarcar un siglo, concretamente el siglo XVIII, optamos por modular el siglo XVIII en tres secciones, que nos ayudarían a tomar una muestra bastante amplia de la centuria, trazando tres ejes que abarcarían 60 ańos: 1700-1720, 1740-1760, 1780-1800.

Se analizan 76 expedientes, sobre un total de 181 para todo el siglo (del 86, año 1704, al 267, año 1800) en el Archivo Municipal Onubense o Archivo Diocesano con información relativa al pueblo de Ayamonte.

El análisis de la información se hará a través del análisis de expedientes, lo que permitirá indagar e interpretar las experiencias de vida de las mujeres y hombres que contrayeron matrimonio en el ámbito familiar.

Los instrumentos utilizados para realizar la labor investigadora se basan en el estudio de archivos o expedientes, concretamente se utilizó una ficha empleada a modo de plantilla para extraer los datos más significativos de cada expediente, tal como puede observarse en el anexo I. 


\section{JUSTIFICACIÓN O ARGUMENTACIÓN}

\section{1. MATRIMONIO Y PARENTESCO}

Atendiendo al estudio de Bestard $(1998)^{4}$, las relaciones entre parientes quedan catalogadas dentro de unas coordenadas temporales, dónde pasado y presente adquieren el rol definitorio a la hora de perfilar la memoria familiar y por ende, de la personal. Dado que los antepasados organizan la narración genealógica que definen una sección del individuo, es imposible evaluar la familia como unidad social, sin hacer referencia a su historia, a ese pasado, más o menos remoto, que construye la identidad de cada individuo.

Es interesante analizar como nuestra cultura ha creado conceptos tales como sangre, raza, carne, árbol o tronco, adscritos sin lugar a dudas, a la construcción moral de la persona y a los principios de identidad social. En relación a esto destacan dos símbolos-conceptos, estrechamente vinculados a tal identidad: tierra y sangre, que revelan como parentesco y residencia quedan mimetizados dentro de los valores de cada sociedad, de cada grupo humano. El concepto tierra ha de ser entendido bien como enclave físico, como lugar, como microsociedad, bien como patrimonio, como propiedad, como legado o herencia.

Dado el enorme peso que en la cultura occidental ha tenido la religión a la hora de concebir el parentesco, es decisivo buscar los orígenes que marcan las relaciones entre parientes. Una parentela, como indica Imizcoz Beunza ${ }^{5}$, no es un grupo en el sentido sociológico del término, sino más bien una categoría de cognados, un conjunto de personas que tienen en común la característica de estar todos emparentados, en diferentes grados, con la misma persona.

Los matrimonios que tiene lugar dentro de la parentela tienen la característica de reducir los grados ascendientes y los colaterales, facilitando la consolidación de las parentelas desde un punto de vista social. Si por ejemplo tiene lugar un matrimonio entre primos hermanos, en la tercera generación de la parentela de sus hijos sólo habrá seis ascendientes, en lugar de los ocho que habría si el matrimonio se hubiera producido fuera de la parentela. Con este tipo de matrimonio disminuye, pues, la capacidad de producir colaterales. Todo matrimonio cercano tiene el efecto negativo de no crear nuevos parientes y el efecto positivo de consolidar los que ya tenía. Esta capacidad de consolidar troncos familiares propios de matrimonios entre colaterales, facilitaría asimismo la existencia de redes de parentesco estrechamente solidarias.

Dado que el parentesco se calcula según una base cognaticia y que ser pariente es algo relativo a la mayor o menor distancia en relación a un antepasado común, las reglas relativas a las prohibiciones matrimoniales se expresan en términos de grado de impropiedad más que en término de prohibición absoluta. La mejor expresión de estas prohibiciones reside en la regla según la cual los matrimonios no deben realizarse "ni demasiado cerca" (en términos de parentesco) "ni demasiado lejos" (en términos sociales). Dicha regla presenta los dos polos a los que se ven abocadas las alianzas matrimoniales en este tipo de sociedades: un polo de seguridad, en los límites más cercanos de la consanguinidad que consolidaría las ventajas conseguidas gracias al otro polo, el de riesgo, que dispersaría las

4 BESTARD, 1998, pp. . 79-112,

5 IMÍZCOZ BEUNZA, 2009, pp. 135-157. 
alianzas más allá de cualquier límite social. Este punto medio ideal expresa la contradicción en las que se ven inmersas las familias cuya reproducción no puede hacerse entre los de misma sangre, pero debe hacerse entre iguales, entre los de la misma clase o de mismos medios. El resultado de este juego sutil de alianzas matrimoniales sería la homogamia social, que combina ciclos cortos en la parentela con alianzas fuera de cualquier consideración de parentesco.

Esta posibilidad de emplear la parentela en las estrategias matrimoniales explicaría la tensión entre una visión del sentido de las prohibiciones matrimoniales por parte de la Iglesia y una visión laica de la parentela.

Las dispensas matrimoniales que otorgaba la Iglesia fueron una clara expresión de su importancia en las prácticas matrimoniales que tenían en cuenta la parentela cercana para la consolidación o la defensa de sus adquisiciones. En este sentido, la endogamia mediterránea del sur de Europa más que una tendencia a repetir matrimonios cerrados en el seno de un mismo tronco familiar, puede definirse como una posibilidad de mantener a las hijas lo más cerca posible de lo que permiten las prohibiciones estrictas del incesto, sin prejuzgar el uso que pueda hacerse de los lazos de parentesco, sociales o de vecindad, para la consecución de las alianzas matrimoniales.

Tal y como señala Gandía Barber $(2007)^{6}$, la Iglesia para justificar las prohibiciones matrimoniales principalmente se basaba en dos razones, una de carácter moral y otra de carácter social. Las razones de tipo moral eran relativas a la unión sexual entre el hombre y la mujer, insistiendo en la contradicción entre la unión en la misma carne a través del acto sexual y la identidad entre dos personas que eran de la misma sangre. De esta oposición surgió la idea de que si se añadía la sexualidad a la relación entre consanguíneos, la libido podía aumentar y los frutos de tales uniones podían ser monstruosos. Los canonistas de la Iglesia consideraron que el matrimonio posibilitaba la creación de un nuevo lazo fraternal a partir del modelo de la unión natural entre hermanos, proyectando el ideal de fraternidad en la esfera de la afinidad. El mismo autor afirma que la unitas carnis entre esposos era una transformación en el terreno de la alianza de la ya existente unitas sanguinis entre hermanos en el terreno de la consanguinidad. La unión conyugal no podía llevarse a cabo entre personas ya unidas por la consanguinidad, sino que debía hacerse entre personas exentas de lazos de sangre. Esta concepción del matrimonio como una fraternidad fuera de la consanguinidad condujo a negar en el terreno moral, la sexualidad conyugal. San Agustín se basa en ella para plantear un ideal de matrimonio en el que entre los esposos no existe más que el amor fraterno, idea que va en consonancia con la denigración que el cristianismo asigna a la sexualidad. La idea de que el matrimonio une a dos personas en la misma carne a la manera de dos hermanos, explica que las prohibiciones matrimoniales se extendieran también al parentesco por afinidad. Esta idea de hermandad se desarrollo asimismo en el parentesco espiritual, aumentando las prohibiciones matrimoniales.

6 GANDÍA BARBER, 2007, pp. 221-238.

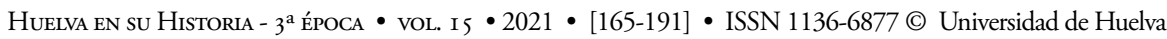


En cuanto a la justificación social de las prohibiciones matrimoniales, las alianzas matrimoniales eran vistas de forma positiva, ya que potenciaban la unidad fraternal de toda la sociedad cristiana. Los matrimonios fuera de la parentela aumentaban las relaciones sociales de la familia, ya que la afinidad creaba nuevos lazos al renovar los lazos de consanguinidad. El sacramento del matrimonio, a imagen de la unión entre Cristo y su Iglesia, se había instituido como el medio de reconstruir esa fraternidad original que el tiempo se iba encargando de destruir. El parentesco se consideraba como una relación social generadora de fuertes vínculos entre las personas. Unos vínculos que se iban diluyendo con el tiempo, por ello las alianzas matrimoniales eran el recurso empleado en el punto de ruptura de las relaciones sociales creadas por la consanguinidad. El matrimonio era considerado como un ciclo que renovaba los lazos de consanguinidad al tiempo que mantenía unido a los hombres. Esta teoría de la alianza matrimonial en el punto de ruptura de la consanguinidad suponía una redundancia de papeles dentro de los grados prohibidos.

No parece que todas las capas sociales aceptaran la extensión de las prohibiciones matrimoniales tal como la propugnaba la Iglesia. En el siglo IX se produjo un cambio del modo de calculo romano por el germánico, manteniéndose el límite del séptimo grado, lo que acarreó vivas tensiones entre los fieles, pues la memoria genealógica y la solidaridad social entre la gentes sin intereses patrimoniales se limitaban al tercer grado de parentesco.

En 1215, en el IV Concilio de Letrán, se limitó al cuarto grado las prohibiciones matrimoniales por causa de consanguinidad o afinidad.

El esquema oficial prohibió el matrimonio entre parientes cercanos, pero tales matrimonios continuaron llevándose a cabo en cantidades significativas.

Las Reformas protestantes consideraron las prohibiciones matrimoniales y la necesidad de dispensas como una intromisión de la Iglesia en el dominio doméstico de las familias. Tanto Lutero como Enrique VIII acusaron a la Iglesia de crear unas leyes propias, opuestas a las leyes de Dios con afán de lucro. Por su parte la Iglesia contraatacó, estableciendo en el Concilio de Trento (1545) las prohibiciones hasta el cuarto grado de consanguinidad y afinidad, conservando el recurso de las dispensas para los grados prohibidos. En cuanto a las razones para justificar tales prohibiciones, dejaron de buscarse en la ley divina, pasando a ser la ley natural la que mantenía una repulsa moral hacia el incesto.

La polémica que suscita delimitar las prohibiciones matrimoniales según las leyes naturales se prolongaron hasta el siglo de las luces. Montesquieu ${ }^{7}$ en el Espiritu de las Leyes (Libro XXVI, cap. XIV) advierte: "respecto a la prohibición del matrimonio entre parientes, es extremadamente delicado fijar el punto en que la naturaleza acaba y las leyes civiles empiezan».

Aunque la repulsa moral hacia los matrimonios cercanos se mantuvo, la biología, ya en el siglo XIX, proporcionó una empírica justificación racional a la creencia en los efectos malignos de los matrimonios entre consanguíneos, restringiéndose las prohibicio- 
nes, confiando en que las consideraciones externas al parentesco dominarían las alianzas matrimoniales.

Aún más, como sugiere Gómez García $(2008)^{8}$, la representación universal de la prohibición del incesto, así como las concretas exigencias del parentesco que el incesto instaura y en las que se reglamenta, es definido por el autor como una función de intercambio en y entre los grupos humanos. Su objetivo consiste en instaurar el matrimonio, estructurado como un sistema de donaciones y contradonaciones. En efecto, el cometido del intercambio se comprende como aquel hecho social que no se reduce al intercambio de mujeres, sino como un fenómeno primitivo y completo que incluye diversas tipos de patrimonios culturales: bienes materiales y valores sociales, entre los que destaca como el bien más preciado las mujeres.

Las relaciones de la familia con son sus allegados articulaban una economía compleja y continuada de intercambios de servicios, prestaciones mutuas, ayudas y reciprocidades, situándose en primer lugar las relaciones de parentesco, ya fuera consanguíneo, de alianza o espiritual.

Las familias eran los centros de unas redes de relaciones muy densas. Vivían rodeadas por los parientes de ambos cónyuges, siendo estos parientes a la vez vecinos, amigos y compañeros de trabajo. Especialmente en las sociedades tradicionales el parentesco desempeña un importante papel, ya que a través de sus prestaciones, intercambios y conflictos, los parientes son un elemento clave en la construcción de las economías domésticas.

Aquellas personas dedicadas al estudio de la antropología e historia han incidido en la importancia del parentesco en la vertebración de las sociedades tradicionales. Dicho parentesco se creaba a través de los matrimonios, de modo que los enlaces del pasado y del presente configuraban el núcleo central de las relaciones de la familia. La endogamia matrimonial contribuía a configurar grupos de parentesco bastante densos, en los que los parientes de una familia eran generalmente parientes entre sí, hallándose ligados muchas veces por parentescos múltiples. Era frecuente observar cómo hermanos, primos, cuñados, yernos, tíos y sobrinos cooperaban en los negocios o practicaban intercambios de bienes y servicios. Las manifestaciones de ayuda, protección y colaboración entre los parientes más allegados estaban presentes en todos los aspectos de la vida, siendo frecuente entre ellos los negocios comunes, los favores mutuos, los préstamos de dinero, reparto de cargos, protección del patrimonio frente a los acreedores, intermediación en los negocios, representación por poderes, padrinazgo espiritual, testimonios en pleitos, mediación en los conflictos...

Las alianzas entre los grandes señores configuraban unas redes de parentesco que vinculaban a una parte de las casas más preeminentes de una comunidad o de un mismo reino. Los diferentes vínculos de parentesco articulaban redes más o menos amplias que se prolongaban mediantes relaciones de amistad y de clientelismo.

El parentesco implicaba unas obligaciones con respecto a los parientes, lo que se expresaba en el término de deudo. Por sus implicaciones y significado, existía una notable cultura del parentesco. Los individuos tenían un conocimiento de sus deudos, que eran

8 GÓMEZ GARCIA, 2008, s.p. 
notorios, de dominio público. En ocasiones, las alianzas matrimoniales tendían a producirse en el seno de unos vínculos anteriores, reproduciendo o reforzando las alianzas de parentesco que cohesionaban al grupo. De esta forma los negocios comunes, los intereses mutuos y los intercambios satisfactorios eran reforzados mediante nuevas alianzas matrimoniales, de tal modo que las relaciones familiares y de parentesco no dependían únicamente de los afectos, sino que estaban muy relacionadas con unos intereses comunes.

Asimismo, atendiendo al enorme peso que en la cultura occidental ha tenido la religión católica en la organización de nuestras concepciones del parentesco, nos parece acertado buscar los orígenes religiosos de estas ideas. Los textos eclesiásticos sobre la justificación de las prohibiciones matrimoniales, la polémica surgida durante la Reforma en torno a estas prohibiciones y las posteriores justificaciones laicas del límite de la consanguinidad nos ayudarán a entender ciertos conceptos en torno a la familia y el matrimonio.

A lo largo de la historia la Iglesia ha reflexionado y legislado acerca del hecho de la consanguinidad en relación al matrimonio, dando respuesta a los diferentes problemas que sobre él se han planteado en las diversas situaciones históricas. La prohibición del matrimonio en ciertos grados de parentesco por parte de la Iglesia estaba acompañada, como advertimos en capítulos anteriores, de una legislación civil paralela con consecuencias penales que prohibía el incesto o la exclusión del matrimonio entre personas en razón de su parentesco.

La historia nos muestra la enorme preocupación que se sentía por los impedimentos de parentesco, con especial énfasis por el de consanguinidad, motivado por tres causas principalmente; el fomento de las relaciones sociales, la protección de la familia y el temor a una posible degradación de la especie.

El problema de la extensión del impedimento, de la forma de computación, la dispensa, la naturaleza jurídica de los diferentes grados y la obligación de aplicar la ley a los casos de uniones fraternas y los motivos que sustentaban el impedimento han sido tratados y debatidos largamente por la doctrina, Concilios (provinciales y generales), respuestas de las Congregaciones Romanas y pronunciamientos Pontificios, generando respuestas puntuales a este fenómeno que intentarían ajustarse a los mandatos de la realidad social.

Creemos conveniente mencionar las razones que sustentan la prohibición de determinados enlaces matrimoniales entre consanguíneos por la Iglesia. Se trata de tres razones que han servido para justificar el impedimento a lo largo de la historia y que componen el sustrato moral de las prohibiciones dictadas por la comunidad eclesiástica. Nos basamos en el texto de Gandía Barber ${ }^{9}$ para describir cuales eran los fundamentos de los impedimentos.

a) La razón profiláctico-eugenésica: Las relaciones carnales entre consanguíneos está presente en casi todas las culturas y pueblos, penalizando y castigando con mayor o menor severidad a los transgresores, ya sea desde el concepto de tabú, ya sea desde la costumbre o desde la ley positiva. Una de las primeras razones 
históricas es evitar la degeneración de la especie, se trata de un argumento popular cimentado sobre la constatación precientífica de los efectos perniciosos para la sociedad. En efecto, las uniones entre parientes cercanos tan sólo aumentan la probabilidad de que se produzca una degeneración, acrecentada en la medida en que se repitan las uniones la probabilidad de que puedan darse malformaciones físicas y psíquicas en la descendencia.

b) La difusión de la caridad o razón social: La prohibición de contraer con los parientes más estrechos (padres con hijos y éstos entre sí) se evitaban con la prohibición del incesto, pero en los demás grados, donde la familiaridad no era tan estrecha, se fundamentó el impedimento con el argumento de la difusión de la caridad. Este argumento, desde su formulación en la Ciudad de Dios de San Agustín, ha sido una razón utilizada para explicar la extensión de la prohibición del impedimento. Razón cuya finalidad es que no se desnaturalice la identidad propia de la familia caracterizada por la generación y el parentesco, encerrándose dentro de sí misma, sino que se abra a otras familias. Cuanto más se extienden los grados de la prohibición del matrimonio entre consanguíneos, afines y otros parentescos, más se extiende la necesidad de buscar consortes en otros grupos humanos. La Iglesia abogando por el bien social en un momento histórico cuya tendencia era casarse entre los miembros de la misma parentela, realizó una progresiva extensión de la prohibición de contraer matrimonio entre parientes, hasta alcanzar la séptima generación en computación canónico-germánica. Así se obligaba a buscar cónyuge al margen del grupo familiar, fomentando el ensanchamiento de dichos grupos y el encuentro-unión con otros clanes.

Cuando tal extensión originó verdaderos problemas que podían desembocar en disputas familiares, la Iglesia mediante el IV Concilio de Letrán reformará la ley rebajando el impedimento al cuarto grado en cómputo romano.

c) Protección de la familia. Es uno de los motivos principales que sustenta el impedimento. La Iglesia prohibió el matrimonio entre parientes cercanos con un objetivo claro: la protección de la dignidad y el carácter específico de la cercanía familiar fomentando el ejercicio de la virtud de la castidad entre aquellos que viven en un estrecho contacto. De este modo, la legislación tanto Estatal como Eclesial ha evitado que las relaciones sexuales entre parientes lesionen los principios morales y desvirtúen las relaciones familiares, caracterizadas por una serie de rasgos afectivos de tipo fraterno-filiar incompatibles con las características que surgen y se requieren para el matrimonio.

Así, dependiendo del modelo familiar dominante, los límites del impedimento han sido modificados en varias ocasiones. En un momento en que las relaciones familiares se reducen a la familia nuclear, también se reduce la limitación del impedimento al cuarto grado en computación romana (primos hermanos inclusive)

No existe pues una razón exclusiva que justifique el impedimento de consanguinidad, sino que es todo este conjunto el que hace conveniente y necesario imposibilitar el matrimonio a ciertos grados, bien porque atenta contra la esencia misma del matrimonio eclesiástico o bien porque se quiere preservar la esencia de la familia, moralizando las relaciones íntimas entre sus miembros. 


\section{Los grados del Levítico y su naturaleza}

Gandía Barber, citado anteriormente, señala que no todos los grados descritos en El Levítico son de Derecho Divino, de manera que no obligan a los cristianos. En la Ley Evangélica sólo permanecen los preceptos morales que tienen la naturaleza de Ley Natural atendiendo a los fines del matrimonio. Estos fines sólo se cumplen en algunos grados de los descritos en el libro del Levítico, luego no todos los casos del Libro Sagrado pertenecen al Derecho Natural. La naturaleza jurídica de cada uno de los grados consanguíneos son:

a) Matrimonio entre padres e hijos: Contradice el fin del matrimonio (procrear y evitar la concupiscencia), en consecuencia están prohibidos por el Derecho Natural y Divino ya que contradice la reverencia, pudor y honestidad que los hijos deben a los padres y por otro lado de no existir tal prohibición existiría un peligro real de aumentar el deseo libidinoso dentro de la misma familia.

b) Entre abuelos y nietos: Sirven los mismos argumentos que para padres e hijos, no se puede contraer matrimonio ni con dispensa del papa.

c) Uniones entre hermanos: el Derecho Natural lo prohíbe, de manera que si se llevara a cabo resultaría nulo, sin que la Iglesia pudiera validarlo. Al tener la misma sangre, haberse nutrido de la misma leche y educado en la misma moral y costumbres si no se impidiese estas uniones sería fácil que éstas creciesen.

d) Uniones de tíos con sobrinos y entre primos hermanos: no se puede demostrar que este tipo de matrimonio contradiga los fines del matrimonio, ya que entre ellos no existe tanta relación para que el matrimonio sea deleznable, de manera que el pontífice puede dispensarlos.

\section{Dispensas pontificias}

Para poder contraer matrimonio en circunstancias especiales el Derecho Eclesiástico generó las dispensas pontificias cuyo cometido era determinar si un determinado enlace podía o no llevarse a cabo en pos del decoro, la piedad y la honestidad de la época.

3. Corpus de análisis: expedientes estudiados en el archivo diocesano de Huelva

Como afirmamos anteriormente, dentro del Archivo Diocesano de Huelva hemos consultado la sección Matrimonios apostólicos, donde se ubican las dispensas solicitadas a la Curia Romana para que se le dispensase el determinado grado de consanguinidad o afinidad. Constan tanto de la solicitud de la dispensa como de la Bula papal que se emitía una vez dispensado el grado, así como el Auto y la Penitencia pública que se imponía a los contrayentes.

El Índice de matrimonios recoge el nombre de los contrayentes y el año en que se solicitó o emitió la dispensa. Existen 6 tomos para Ayamonte distribuidos de la siguiente manera:

Tomo 1 (Expedientes del 1-80),

Tomo 2 (Expedientes del 81-160),

Tomo 3 (Expedientes 161-192), 
Tomo 4 (Expedientes del 193-220),

Tomo 5 (Expedientes del 221-280) y

Tomo 6 (Expedientes de 281-326).

Salvo el primero, hemos consultado los restantes.

Si hemos de citar dos obras que han servido de base para nuestra investigación, sin lugar a duda, son Demografia y Análisis Histórico. Ayamonte 1600-1860 de José Luis Sánchez Lora y En los confines del reino. Huelva y su tierra en el siglo XVIII de Francisco Núñez Roldán. 1701- 1 EXPEDIENTE. 1753-2 EXPEDIENTES. 1778- 1 EXPEDIENTE. 1704- 1 EXPEDIENTE. 1754-2 EXPEDIENTES. 1780- 1 EXPEDIENTE. 1705- 1 EXPEDIENTE. 1755- 1 EXPEDIENTE. 1781- 1 EXPEDIENTE. 1711- 1 EXPEDIENTE. 1756- 2 EXPEDIENTES. 1782- 1 EXPEDIENTE. 1713- 2 EXPEDIENTES. 1757- 4 EXPEDIENTES. 1785- 2 EXPEDIENTES. 1714- 2 EXPEDIENTES. 1758- 2 EXPEDIENTES. 1786- 1 EXPEDIENTE. 1715- 4 EXPEDIENTES. 1759- 3 EXPEDIENTES. 1787- 4 EXPEDIENTES. 1720- 2 EXPEDIENTES. 1760- 2 EXPEDIENTES. 1788- 2 EXPEDIENTES. 1722- 4 EXPEDIENTES. 1761- 1 EXPEDIENTE. 1790- 3 EXPEDIENTES. 1726- 1 EXPEDIENTE. 1762- 2 EXPEDIENTES. 1791- 4 EXPEDIENTES. 1729- 1 EXPEDIENTE. 1763- 5 EXPEDIENTES. 1792- 2 EXPEDIENTES. 1730- 2 EXPEDIENTES. 1764- 2 EXPEDIENTES. 1796- 3 EXPEDIENTES. 1731- 3 EXPEDIENTES. 1765- 10 EXPEDIENTES. 1797- 1 EXPEDIENTE. 1732- 1 EXPEDIENTE. 1766- 24 EXPEDIENTES. 1798- 1 EXPEDIENTE. 1733- 2 EXPEDIENTES. 1767-14 EXPEDIENTES. 1799- 2 EXPEDIENTES. 1735- 1 EXPEDIENTE. 1768-11 EXPEDIENTES. 1800- 2 EXPEDIENTES. 1740- 3 EXPEDIENTES. 1769- 6 EXPEDIENTES. 1741- 2 EXPEDIENTES. 1770- 2 EXPEDIENTES. TOTAL= 1745- 2 EXPEDIENTES. 1771- 4 EXPEDIENTES. 181 MATRIMONIOS 1746- 1 EXPEDIENTE. 1772- 4 EXPEDIENTES. 1747- 3 EXPEDIENTES. 1773- 1 EXPEDIENTE. 1749- 2 EXPEDIENTES. 1774- 1 EXPEDIENTE. 1750- 1 EXPEDIENTE. 1775- 2 EXPEDIENTES. 1751-1 EXPEDIENTE. 1776- 5 EXPEDIENTES. 1752-1 EXPEDIENTE. 1777- 2 EXPEDIENTES.

Matrimonios extraídos del Índice de matrimonios sito en el Archivo Diocesano de Huelva. 1700-1800

Para el análisis documental que a continuación emprenderemos, nos hemos apoyado en los datos extraídos del estudio de la nupcialidad que el doctor Sánchez Lora llevó. Para tal estudio contó con varias fuentes: Entre las fuentes eclesiásticas destacan los libros sacramentales de las dos parroquias existentes en Ayamonte, durante el periodo estudiado: El Salvador y Las Angustias, que extendían su jurisdicción sobre los dos barrios fundamentales de la ciudad: La Villa y La Ribera, respectivamente.

En el caso de Las Angustias, la serie de matrimonios no presenta más interrupción que la comprendida entre 1745 y 1774, ambos inclusive. Para el caso de El Salvador, en las series no falta una sola partida, iniciándose en 1600. 
De igual manera, el autor, hace constar su decepcionante búsqueda de los padrones de cumplimiento pascual. No apareció ninguno en El Salvador, y sólo uno en Las Angustias, aunque para una fecha ya tan tardía como 1860.

Del Archivo Municipal también extrajo una gran variedad de información. El grueso de la documentación municipal lo constituyen las actas capitulares, cuyo primer libro se inicia a mediados del siglo XVI.

Nuestra metodología de trabajo, como ya dijimos, en un intento de acaparar todo el siglo, consistía en realizar tres módulos o cortes de 20 años cada uno, centrados a principio, a mediados y a finales de la centuria. Así, en cada cala hemos analizado los siguientes expedientes:

\begin{tabular}{|c|c|}
\hline AÑO & NÚMERO DE MATRIMONIOS. \\
\hline $1646-1745$ & 38,7 matrimonios. \\
\hline $1701-1702$ & 22 matrimonios. \\
\hline 1707 & 12 matrimonios. \\
\hline $1711-1712$ & 21 matrimonios. \\
\hline $1775-1850$ & 46 matrimonios. \\
\hline
\end{tabular}

Tabla 1 Fuente: Elaboración propia.

$1700-1720=12$ expedientes ( $\left.\mathrm{n}^{\circ} 86-98\right)$

$1740-1760=34$ expedientes $\left(n^{\circ} 114-143\right)$

$1780-1800=30$ expedientes ( $n^{\circ} 246-266$ )

Total de expedientes analizados $=76$ expedientes

Por otro lado hemos calculado los matrimonios celebrados en las dos parroquias, siguiendo los cortes de nuestro estudio. Serían los siguientes:

El porcentaje que las dispensas suponen sobre el total de los matrimonios son las siguientes:

El índice de matrimonios consultado en el citado archivo nos muestra un total de 181 expedientes de dispensas matrimoniales para el siglo XVIII (expedientes del 86 al 266). Se han dado casos en el que existen varios expedientes con una misma numeración, o

1700-1720. 1740-1760. $\quad$ 1780-1800. Total de matrimonios

\begin{tabular}{lllll}
\hline Las Angustias. & 468 & 165 & 815 & 1448 \\
El Salvador. & 244 & 291 & 213 & 748 \\
\hline
\end{tabular}

Tabla 2 Fuente: Elaboración propia, atendiendo a las series parroquiales. 
bien lo hemos tenido que sacar del estudio ya que se sale de nuestros límites cronológicos, como es el caso, por ejemplo, de los dos expediente número 88, uno de 1649 y otro de 1671.

$\begin{array}{cccc}1700-1720 . & 1740-1760 . & 1780-1800 . & \text { Total matrimonios. } \\ \text { (12 dispensas) } & (34 \text { dispensas }) & (30 \text { dispensas }) & \text { (76 dispensas). }\end{array}$

Las Angustias.

El Salvador.

\begin{tabular}{|c|c|c|c|c|}
\hline Total & 12 dispensas & 34 dispensas & 30 dispensas & 76 dispensas \\
\hline
\end{tabular}

Tabla 3 Fuente: Elaboración propia.

A simple vista, consultado el indice de matrimonios, hemos podido observar una peculiaridad, entre 1765 y 1770, se solicitan un total de 67 dispensas, una cifra que se sale de la media, atendiendo a los demás ańos. En 1766 podemos apreciar la cifra de 24 expedientes y en 1767, 14 expedientes. Teniendo en cuenta que en los años previos y en los posteriores a este periodo, rara vez se sobrepasan los 4 matrimonios, existiendo una media de 1 a 2 dispensas por ańo, es significativo el elevado índice del periodo. A pesar de que este ańo no entran en nuestra cala, hemos pasado someramente por los expedientes del año 1766 (el año que cuenta con más expedientes en todo el siglo), observando la particularidad que en 21 de los 24 expedientes, los contrayentes son naturales del obispado de Pharo, es decir, son inmigrantes portugueses, destacando en todos estos casos que son vecinos de Ayamonte desde hace más de cuatro meses. En el año 1767 existen, la discordante cifra con la tónica general, de 14 expedientes, para 1968 hay cifrados 11 expedientes, para el siguiente año 6 expedientes y ya parece que se recuperan los valores medios que no exceden de 4 dispensas. Por lo tanto, el lustro de 1965-1969, acapara cifras que elevan desmesuradamente la cifra de dispensas matrimoniales solicitadas en el siglo XVIII en Ayamonte. Hemos acudido al apartado dedicado a la inmigración de la citada obra de Sánchez Lora para intentar buscar una explicación a este fenómeno pero justo para esa fecha no nos aporta ningún dato, ninguna cifra sobre la llegada de forasteros a las lindes ayamontinas, indicando al respecto que el periodo que registró un mayor porcentaje de forasteros casados en la localidad de todo el siglo fue el periodo de 1775-1799.

Todos los expedientes presentan los mismos apartados, son un formulario estándar y homogéneo que constan de las mismas partes, que se repiten una y otra vez, firmados por las autoridades competentes, no observando ninguna variación sustancial a lo largo de todo el siglo. De igual modo, en la mayoría se conserva la Bula dónde se le concede la dispensa a los contrayentes, y en algunos casos la fe de bautismo de los contrayentes, la partida de fallecimiento del cónyuge anterior, certificados médicos... como documentos anexos.

El estado de conservación es medianamente bueno, salvo algunos casos, dónde más a causa de la letra ilegible que a otra cosa, nos ha resultado bastante laborioso extraer el contenido. 
El archivo no dispone de indice de matrimonios para Lepe, La Redondela, Isla Cristina, ni San Silvestre.

\section{ANÁLISIS DE LOS DATOS}

A partir del procesamiento y análisis de la información recogida, se obtienen resultados respecto de la sociedad ayamontina, desvelando características de los procesos de matrimonios endogámicos. A continuación se analizarán los siguientes indicadores que permitirán sacar algunas conclusiones.

\section{Los contrayentes. Origen}

En este apartado hemos de hacer una distinción entre naturales y vecinos. Cuando se habla de que el susodicho es natural de, nos referimos a su origen, es decir el lugar dónde nació, pasó sus primeros años o un determinado tiempo. La vecindad es el domicilio actual, donde residen.

En sociedades tan cerradas como las del Antiguo Régimen, es trascendental poseer ciertas referencias familiares, que la vecindad conozca los antecedentes familiares del individuo es uno de los rasgos que marcará la estima u honradez o la crítica y la deshonra. Hay cierta desconfianza hacia el extranjero, al de afuera, ya que se desconoce su linaje, su genealogía y todo lo que con ello va parejo (situación económica, currículo religioso...). En todos los expedientes queda patente, a la hora de presentar a los individuos, que no ha hecho ausencia notable de la ciudad y si lo hubiera echo, se explicita el tiempo que estuvo fuera y dónde fue. En el estado de desconfianza general en el que se vivía donde todos se vigilaban entre sí, suponemos que se debía temer que al abandonar la villa por un periodo largo de tiempo se podría llevar una doble vida, mantener relaciones inadecuadas, volverse a casar en el caso que ya lo estuviera...

Existen, al menos un par de casos en el que el contrayente estuvo en Indias, pasando previamente por la ciudad de Cádiz (expediente 93, 128). En estos casos en el Auto se manda a declarar a varios testigos que justifiquen la ausencia de la ciudad. En el expediente 128 uno de los testigos (Juan Francisco Fernández) nombrados para tal caso afirma que desde que salio de Cádiz en Puerto Rico, la Veracruz y la Habana, nunca en estos puertos desamparó su navío ni perdió su plaza y así siempre se ha conservado.

La mayoría son naturales y vecinos de Ayamonte, aunque no todos. Encontramos a algunos que proceden de ciudades aledañas como Sanlúcar de Guadiana, San Silvestre de Guzmán, Lepe, Huelva, San Juan del Puerto o no tan vecinas como Sanlúcar de Barrameda. La inmigración portuguesa cobra especial relevancia: encontramos a personas naturales de Lagos, Faro o Castro Marín (término del obispado de Faro en Portugal).

\section{Profesión}

Ya que en una gran proporción de casos, tratamos con individuos (ellos) que se dedican a actividades pesqueras o marineras (hombres de mar), o incluso en un caso un miembro de la armada de su magesta, es frecuente que se trasladen de un lugar a 
otro según la temporada o sus intereses, por lo que podemos decir que, en nuestro caso, no podemos hablar de una sociedad estática, sino que hay una cierta movilidad (controlada).

Las profesiones de ellos, en la mayoría de los expedientes no se especifican, no sabemos si por carecer de un oficio concreto o por simple omisión voluntaria. En bastantes casos se alude a la condición humilde del contrayente: «dichos contrayentes son pobres y miserables $\mathrm{y}$ viven de su industria y trabajo personal»; pero sin especificar el trabajo, suponemos que se tratan de individuos que se dedican a labores temporales, a actividades puntuales para sobrevivir, sin ninguna especialización. No obstante nos hemos encontrado con varios profesionales: vendedor de tabaco, herrero, marinero u hombre de mar y un capitán.

En dos expedientes ( $n^{\circ} 116$ y 125), a la hora de establecer a que se dedican tanto los contrayentes como los testigos se destaca el hecho de que son gitanos vagantes

Las profesiones de ellas tampoco quedan demasiado patentes, tenemos el caso de una costurera, las demás quedan sin especificar.

\section{Edad}

Nos resulta curiosa la forma de matizar ciertas edades con lo de poco más o menos, es decir que no poseían la entera certeza de que se tuviera una determinada edad, ni siquiera, deducimos, el propio sujeto que lo indicaba.

La franja de edad para los hombres es algo más elevada que para las mujeres. Digamos que va desde los 24 a los 50 ańos. El caso más joven tenía 19 y el mayor 53 (expediente $\left.n^{\circ} 119\right)$, estando la edad media entre los 20-30.

Para las mujeres, los 24 ańos era un tope para tildar de urgente la necesidad de casarse, si a esa edad no lo habían hecho, resultaba cuanto menos sospechoso. La edad media que extraemos de los expedientes es de los 17-24.

La edad más avanzada que hemos constatado son 53 años (expediente no 119), se trata de dos viudos naturales que optan por casarse ya que por ser corto el pueblo no hallara la susodicha varón de su igual condición, ignorando ella su parentesco.

\section{Grado de consanguinidad o afinidad}

Existen expedientes dónde los contrayentes tienen en común distintos grados de afinidad o consanguinidad, es decir se puede dar un caso dónde tengan segundo con tercero, tercero con cuarto... En estos casos se incluye dentro del recuento de ambos grados, por ello la suma de los grados de cada corte no encaja con el número de expedientes.

En virtud a estos datos podemos concluir que en los tres módulos los contrayentes solicitan la dispensa mayoritariamente para el cuarto grado de consanguinidad, siguiéndole muy de cerca el tercer grado, sobre todo en el primer y segundo corte.

Sólo nos hemos topado con un caso dónde se da el primer con segundo grado (expediente 261) en el ańo 1796.

Grados de afinidad:

1700-1720: No se da ningún caso.

1740-1760: 1 tercer grado, 2 cuartos grados, 1 tercer con cuarto grado y 1 primer con segundo grado.

1780-1800: 3 primeros grados, 1 segundo con tercer grado y 1 tercer grado. 


\begin{tabular}{|c|c|c|c|}
\hline & $\begin{array}{c}1700-1720 . \\
(12 \text { expedientes })\end{array}$ & $\begin{array}{c}1740-1760 . \\
(34 \text { expedientes })\end{array}$ & $\begin{array}{c}1780-1800 . \\
(30 \text { expedientes })\end{array}$ \\
\hline Primer grado. & - & - & 1 \\
\hline Segundo grado. & 2 & 5 & 4 \\
\hline Tercer grado. & 8 & 15 & 11 \\
\hline Cuarto grado. & 6 & 16 & 17 \\
\hline
\end{tabular}

Tabla 4. Fuente: Elaboración propia.

\section{Causas para solicitar la dispensa}

Existen una serie de causas recurrentes a la hora de solicitar la dispensa que se repiten reiteradamente a lo largo de los expedientes consultados, empleando casi exactamente las mismas expresiones. Las causas más frecuentes son:

-Sospecha de cópula carnal: En este caso encontramos dos variables: los que saben que son parientes y aún así mantienen relaciones sexuales sin ánimo de mover la voluntad de su santidad sino "vencidos por la flaxilidad humana», los que saben que son parientes y se "comunicaron con tanta frequencia que resultó sospecha aunque falsa de copula carnal» y los que ignoraban su parentesco y lo descubrieron bien antes del matrimonio o ya consumado éste. Sirvan algunos ejemplos:

«sabiendo eran tales parientes tuvieron copula carnal y que el haberla tenido no fue con animo de mover más fácilmente a su santidad, para que dispensase con ellos, sino solo fue venzidos y llenados de la flaqueza y flaxilidad humana y que si dicho matrimonio no tuviese efecto, la susodicha quedaría difamada y sin casar de lo que resultaría grave escándalo » (expediente 89).

" con la mucha frecuente comunicación que ha tenido con la susodicha ha habido algunas personas que han sospechado, pero en realidad no ha cometido tal culpa» (expediente 93).

«que los dichos se comunicaron con frecuencia, de la qual a resultado sospecha (aunque falsa) de aver tenido copula carnal, que en realidad no an tenido, pero la sospecha es tal, que si este matrimonio no tuviese efecto quedara la contrayente difamada» (expediente 135).

«los dichos contrayentes sabiendo eran tales parientes se comunicaron con tanta frecuencia que resulto sospecha (aunque falsa) de haver tenido copula carnal, que en realidad no han tenido» ( expediente 185).

- La contrayente no tiene dote o es insuficiente para hallar varón de su misma condición:

«La susodicha no tiene dote alguno para poder casarse con varon según su estado y condición y que el susodicho se quiere casar con ella aunque no la tenga y que la dota enteramente según su estado y condición» (expediente 98).

«La contrayente no tiene dote ni acción por donde ser dotada y que el contrayente se quiere casar con ella aunque no la tenga y que la dota no por modo de nunzias, en 
50 ducados de vellón y que dicha dote es suficiente según el estado y condición de la contrayente" ( expediente 131).

«Que la dicha contrayente no tiene dote alguna ni acción por donde poder ser dotada, que dicho contrayente quiere casarse con ella y dotarla por entero honra en cantidad competente a su calidad digan en quanto ladora y si la tal cantidad es la competente a la calidad y condición de la referida y remítanse a la escritura de dote de la que se traerá copia " (expediente 258(10)).

«la dote de la contrayente es corta e incompetente según su calidad por cuya razón no hallaría varón de su igual condición con quién casarse» (expediente 78).

- Por la estrechez del lugar

«Por la estrechez de vecindad de San Silvestre, por ser corto y de pocos vecinos emparentados todos no hallara dentro del dicho lugar varón de su igual estado, calidad y condición con quien casar que no sea su pariente en consanguinidad» (expediente 87).

«Por ser corto el pueblo no hallara la susodicha varón de su igual condición[...] esta vecindad es de corto vecindario y con la guerra y Armadas de su magestad, aún de mas distracion de sus moradores[...] con lo calamitoso de los tiempos y guerra cada día más aniquilada» ( expediente 119).

- La contrayente es mayor de 24 años

"Que la dicha contrayente tiene ya 24 años hasta cuyo tiempo no ha hallado varon de su ygual clase y condición " (expediente 180).

«la susodicha es mayor de veinte y quatro ańos y que hasta ahora no ha hallado varon de su igual estado y condición con quien casar» ( expediente 127).

"que la dicha contrayente tiene yamas de veinte y quatro ańos de edad hasta cuio tiempo no ha hallado varón de su igual clase y condición con quien casarse que no sea su pariente por consanguinidad o afinidad» (expediente 247).

- Otras. Nos topamos con tres casos consecutivos, en el mismo año (1790), en los que se alega el haber contraído esponsales por palabras de futuro con el cuñado o cuñada: "Que la dicha Juana Díaz contrajo esponsales futuro con su hermano carnal del referido Cayetano (contrayente) lo que después se ha disuelto por mutuo consentimiento» ( expediente 251).

«El susodicho Agustín contrajo esponsales por palabras de futuro con Antonia Palazios, hermana de la contrayente, los quales esponsales por mutuo y espontaneo consentimiento fueron disueltos" (expediente 252).

"Que la dicha contrayente contrajo esponsales por palabras de futuro con su hermano de dicho contrayente, los quales esponsales después los han disuelto por mutuo consentimiento de los dos y se halla la contrayente en libertad de poderse casar con dicho Luis Carlier (contrayente)» (expediente 253).

En otro de los casos, este del año 1791, se alega lo siguiente:

«Que los dichos contrayentes ignorando sea parientes contrajeron matrimonio habiendo precedido las correspondientes diligencias y amonestaciones que previene el Santo Concilio y no habiendo resultado impedimento canonico después de lo qual y de haver consumado el matrimonio tuvieron noticias de ser parientes en cuarto grado 
de consanguinidad, por lo qual se separaron hasta obtener la correspondiente dispensa y que si se divorciaran o separaran resultarían escandaloso» (expediente 256).

Como apreciamos las causas empleadas fluctúan atendiendo el corte. En el primero la insuficiencia de dote y la sospecha de haber mantenido relaciones sexuales tiene valores parejos. En el segundo, toma la cabeza la cortedad de la dote y ya en el tercero vuelve a predominar la sospecha de cópula carnal a la hora de solicitar la dispensa.

La estrechez del lugar no es una causa muy recurrente, como sucede a la que la contrayente sea mayor de 24 años, aunque en la última cala ésta adquiere cierto protagonismo.

\begin{tabular}{|c|c|c|c|}
\hline & $1700-1720$. & $1740-1760$. & $1780-1800$. \\
\hline $\begin{array}{c}\text { La contrayente no posee dote } \\
\text { o la dicha dote es insuficiente }\end{array}$ & 5 & 18 & 9 \\
\hline Sospecha de cópula carnal & 6 & 12 & 14 \\
\hline Estrechez del lugar & 1 & 2 & - \\
\hline La contrayente tiene más de 24 años & - & 1 & 4 \\
\hline Otros & - & $1^{*}$ & $3^{* *}$ \\
\hline
\end{tabular}

Tabla 5. Fuente: Elaboración propia.

* Se trata de un caso dónde se llegaron a casar, consumaron el matrimonio y después se enteraron de su parentesco. Ambos son gitanos vagantes, se casaron en San Juan del Alpechín o la mayor, vivían en Sanlúcar, de donde era natural ella, hasta casarse para finalmente irse a vivir a Ayamonte

** Los expedientes 251, 252 y 253, ambos de 1791, reflejan el compromiso (esponsales de futuro) entre uno de los contrayentes y su cuñadx, habiendo disuelto por mutuo consentimiento dicho acuerdo.

\section{Estado civil}

En un $90 \%$ de los casos ambos contrayentes son solteros. En el caso de ella se recalca: «donzella libre y soltera». Para ambos en boca de los testigos: «son libres y solteros haviles para poder contraer matrimonio que no tiene noticia ayan hecho voto de castidad ni religión ni tienen ningún otro impedimento[...]» (expediente 98).

En buena parte de los casos (expedientes no 114, 117,119,127,134,138, 238, 240, 249, 252, 253) sólo uno de los contrayentes es viudo. En sólo un par de casos ambos son viudos (expediente no 119, 244).

\section{Analfabetos o letrados}

Digamos que sólo una ínfima parte de la población estudiada sabe firmar, y en los expedientes al observar la firma de aquellos que sí saben, podemos apreciar que su trazo no es muy fluido, por lo que no deben practicar la escritura con frecuencia, tratándose como se trata de gente sin formación de origen humilde, en la mayoría de los casos.

\section{Los testigos}

Debemos distinguir dos clases de testigos: por una parte, están los de la información general, y por otra, los de oficio. Los de información general son vecinos de la localidad, allegados, incluso amigos, aportados por los contrayentes y que siempre intentaran fa- 
vorecerles con sus declaraciones. Deben conocer de primera mano a los contrayentes. Suelen ser tres, aunque nos hemos encontrado casos que hay hasta cinco. Existe una franja de edad bastante amplia para ellos, aunque todos superan los 30 años. En cuanto a los de oficio, son dos, personas mayores (entre 50-80), respetables y de crédito, convocados por el cura más antiguo de la villa (también el juez de la comisión), que ofrecen un testimonio fidedigno.

A partir de 1785 podemos observar que la identidad de estos dos testigos no se plasma en el informe como se venía haciendo con anterioridad a semejanza con los testigos de la información general, sino que la comisión da fe de su testimonio: «en cumplimiento de comisión debo informar a vos que los testigos de información [...] son personas fidedignas, de todo crédito y autoridad y a sus disposiciones se les ha dado y da entera fe y crédito en juicio y fuera de él por lo que juzgo han expuesto la verdad[...]» (expediente 244).

En este testimonio se les denomina a los testigos de oficio (in voze): «examine de oficio a dos personas de buena fama y reputación por el thenor de las preguntas del interrogatorio inserto en la dicha comisión y las halle en todo contexto con las deposiciones (¿)de los tres testigos que van extendidas en la información que va susodicha» (expediente 247).

«examino de oficio [...] a mas de tres testigos que han depuesto en la información que va hecha dos personas mas fidedignas y de todo crédito por el thenor de las preguntas de dicho interrogatorio inserto en la comisión, que estuvieron contentos en todo con las declaraciones de los referidos tres testigos» (Informe in vose, expediente 250).

A los testigos se les somete a una serie de preguntas: en primer lugar si conocen a los susodichos, si saben que son parientes y en que grado, si saben si han tenido una ausencia notable del lugar, si saben si han mantenido trato carnal o por la dote, si saben si la susodicha no ha sido forzada ni robada sino que desea casarse por libre y espontánea voluntad y finalmente se acaba diciendo que todo lo anteriormente expuesto es público y notorio, voz y fama.

\section{Autos}

Se trata del acta que confirma la aceptación de los distintos procedimientos emitidos por el Arzobispado, por parte del cura más antiguo de la villa. El auto puede considerarse como el acta que confirma la aceptación o aprobación de la solicitud. A través del notario, que es el que se encarga de llevar a cabo las diligencias oportunas, el cura, expresa la aprobación y obediencia a los mismos y ordena su cumplimiento, así, manda notificar en cada momento a los implicados sus correspondientes intervenciones o aportaciones a lo largo de todo el juicio. Motivo por el cual siempre los autos anteceden a las notificaciones $y$, por supuesto, a cualquiera de las partes que componen el proceso.

\section{Sentencias}

La fórmula más extendida de dar por dispensado el grado de afinidad o consanguinidad es: «dese por verificada la narrativa y en virtud del Breve apostólico se dispensa el [...] grado de [...] y dese mandamiento de amonestar públicamente y anotándose las licencias de los padres» (expediente 255). 
«dese por verificada la narrativa y en virtud del Breve apostólico se dispensa a los contrayentes del cuarto grado y dese mandamiento para que el cura los amoneste y case en la forma ordinaria» (expediente 126).

«dese por verificada la narrativa y en virtud del Breve apostólico se dispensa a los contraientes el cuarto grado de consanguinidad y se declara no obstante la distancia del tercero respecto del dicho quarto y dese mandamiento para que el cura los amoneste y case en la forma ordinaria» (expediente 129(2o)).

\section{Penitencias}

Las penitencias han de ser públicas, es decir todo el pueblo ha de conocer la razón por la cual se impone y las labores acciones que se le encomienda a los que han de cumplirla. La causa de la penitencia, al menos no hemos encontrado otra, la de haber mantenido relaciones sexuales, bien sabiendo el parentesco o ignorándolo.

Una vez que la sentencia dictamine que pueden contraer matrimonios, a los contrayentes se le impone una pena que han de llevar a cabo antes de casarse.

En la casi totalidad de los expedientes encontramos una penitencia anexa al auto, rara vez se obvia el grado sin llevar aparejado una penitencia.

A ambos contrayentes se le impone que: «en un día de fiesta oigan una misa cantada en cuerpo y en pie con velas encendidas en las manos sin arrodillarse si no es a la señal del Santísimo Sacramento [...] que el sacerdote declare al pueblo que la razón de dicha penitencia es para la sospecha falsa de haber tenido copula carnal» (expediente 124).

«acudieron a la parroquia en pie y en cuerpo toda la misa conventual excepto a la elevación del Santísimo Sacramento con velas encendidas en las manos y el publico de la mayor parte del pueblo que aquella penitencia era por haberse conocido carnalmente sabiendo que eran parientes en tercer grado. El contrayente ha estado asistiendo personalmente en otra iglesia a todo lo que se ha ofrecido así en otras pias ocupaciones y todos los días continuamente desde el dia 12 de noviembre. La hora al dia se le dio para buscar sustento por ser pobre [...]» (expediente 86).

A parte de oir esa misa cantada, el contrayente ha de realizar una serie de trabajos a la iglesia al que se adscribe, para pagar su falta. Veamos algunos casos:

«El sacerdote dijo en clara voz la causa de su penitencia ( 4 meses en la obra de la fábrica) [...] dos días el contrayente ha de tocar el Avemaría y el Rosario, asistir a el a llevar los faroles y demás insignias y algunos días daba de comer a los enfermos " (expediente 118).

"por no haber en la parroquia donde es feligres obra ni en otro lugar pio de la ciudad. Que cumpla con los veinte dias signados asistiendo en la dicha iglesia en cuerpo a tocar las campanas ayudar a misa y obras serviles que se han ofrecido en este tiempo [...]» (expediente 90).

«el cura de la parroquia certifica ha asistido por cinco meses continuos a las obras que se le han ofrecido a la fabrica de la dicha iglesia y cuando no las ha tenido a asistido a misa diariamente» (expediente 114).

"penitencia publica de seis meses de trabajo. Por no haber obra en la fábrica el susodicho a de venir a tocar personalmente las ánimas todas las noches» (expediente 120).

En general, los meses de penitencia que más se repiten son 4 . 
«4 meses en la obra de la fábrica de su iglesia o en otro lugar pio que su cura señalase sin comunicarse con la susodicha[... si asi fuese tan pobre que no tenga con lo que alimentarse se le seńalen oras al dia en que cobre o el sustento en la obra [...]» (expediente 124).

El cura, finalmente, tras cumplir la penitencia, debía expedir un certificado dónde especificaba las horas de trabajo y el día en que los contrayentes oyeron la misa cantada. Normalmente, para oir tal misa, se elegía un día de gran afluencia de público (San Isidro Labrador, Santo Tomás...), en la cual los contrayentes eran expuestos a tal penitencia pública, quedando la vecindad enterada de la afrenta.

\section{Conclusiones}

Se trata de una sociedad donde los contrayentes de matrimonio en su mayoría son naturales y vecinos de Ayamonte, aunque no todos. Su nivel socioeconómico es de clase baja, dedicados una gran mayoría a oficios como vendedor de tabaco, herrero, marinero u hombre de mar. Las mujeres se dedican, principalmente, a coser, amas de casa, pero en la mayoría de los casos no se especifica su condición laboral. Son una población mayoritariamente dedicada a la agricultura y a la pesca, como bien puede deducirse de los expedientes.

En cuanto a la edad del matrimonio, para los hombres existe una franja que oscila de 24 años a 50 años. Para las mujeres, la edad media que extraemos de los expedientes es de los 17-24 ańos.

Asimismo, el grado de consanguinidad que existe entre los contrayentes se refleja en la siguiente tabla. Nótese que las relaciones matrimoniales basadas en el tercer y cuarto grado de consaguinidad es más notable que las relaciones de primer o segundo grado. $\mathrm{Al}$ tratarse de una localidad que en el siglo XVIII, no debió superar los 2000 habitantes, las relaciones se estrechaban y se casaban con familiares de sangre lejana.

\begin{tabular}{|c|c|c|c|}
\hline & $\begin{array}{c}1700-1720 . \\
(12 \text { expedientes })\end{array}$ & $\begin{array}{c}1740-1760 . \\
(34 \text { expedientes })\end{array}$ & $\begin{array}{c}1780-1800 . \\
(30 \text { expedientes })\end{array}$ \\
\hline Primer grado & - & - & 1 \\
\hline Segundo grado & 2 & 5 & 4 \\
\hline Tercer grado & 8 & 15 & 11 \\
\hline Cuarto grado & 6 & 16 & 17 \\
\hline
\end{tabular}

Por otro lado, las dispensas matrimoniales que otorgaba la Iglesia fueron una clara expresión de su importancia en las prácticas matrimoniales que tenían en cuenta la parentela cercana para la consolidación o la defensa de sus adquisiciones. En este sentido, la endogamia del sur de Europa fue una tendencia, mediante matrimonios cerrados en el mismo seno familiar.

Como hemos podido comprobar en los expedientes consultados de dispensas matrimoniales, en el Archivo Diocesano de Huelva, en la mayoría de ellos, cuando se llega a constatar que han mantenido relaciones sexuales, bien por testigos, bien por un indeseado embarazo, se aduce ala fragilidad humana para excusar su comportamiento. Tal caso, por 
ejemplo, lo encontramos en el expediente número 86 de 1704, en la dispensa solicitada por Manuel Díaz Blandón y Isabel de Aguilar dónde encontramos este excusa: «flaco y arrebatado de fragilidad cometió el incesto y copula sin otro fin [...]. Vencidos de su fragilidad y miseria y de alguna casualidad y oportuna ocasión cometieron el incesto $[\ldots] »$.

Las causas por las que se motivaban las dispensas eran:

- Tranquilizar la conciencia. En el caso de darse un matrimonio contraído de mala fe ya que los contrayentes conocían el grado del impedimento, los esposos después de un tiempo más o menos largo cohabitando habiendo podido tener descendencia, se dirigen al Papa solicitando la dispensa.

- Evitar el escándalo por la separación de un matrimonio estable. Un motivo que se aduce para solicitar la dispensa es el de evitar el grave escándalo que seguiría a la separación de un matrimonio que ha tenido bastantes años de convivencia, descubriéndose posteriormente el grado de impedimento. Según la ley, éste podría quedar disuelto con la consiguiente ilegitimación de la prole.

- El fin de una situación de escándalo público. En otros casos se busca acabar con una situación escandalosa provocada por una unión incestuosa prolongada en el tiempo.

- La legitimación de la prole. Una de las penas que se aplicaban a los matrimonios incestuosos era la consideración de los hijos como ilegítimos, pena que los hacía inhábiles para obtener ciertos oficios.

- Dispensas para la defensa del más débil. En el caso de quedar viuda una mujer la dispensa le facilitará que pueda contraer matrimonio con un pariente que la ampare a ella, a sus hijos en el caso de tenerlo y a sus posesiones.

Una vez que la sentencia dictaminase que los contrayentes pudieran contraer matrimonios, se les imponía un castigo que habían de llevar a cabo antes de casarse. Las penitencias tenían que ser públicas, todo el pueblo tenía que conocer la razón por la cual se imponía y las labores que se les encomendaba a los que habían de cumplirla. Las causas de las penitencias, al menos no hemos encontrado otra, consistió, principalmente, en haber mantenido relaciones sexuales, bien sabiendo el parentesco o ignorándolo. La penitencia consistía en ir a misa y ayudar a la iglesia en algunas labores para pagar así su falta.

En líneas generales, los datos obtenidos indican que la endogamia familiar en Ayamonte no fue una práctica muy arraigada pero sí una costumbre practicada por una parte de su sociedad, concretamente entre familias de cuarto grado de afiliación. Suponemos que esta práctica fue utilizada, principalmente, por familias acomodadas, en tanto que el Catolicismo prohibía este tipo de enlaces matrimoniales; además, la necesidad de conseguir una dispensa Papal no era factible económicamente para las clases bajas. En el caso de que dos personas siendo familias se casaran y obtuvieran la dispensa sugiere que eran apoyadas o ayudadas por personas del mismo clero o los nobles, ya que las dispensas eran otorgadas por una cuantía económica. 


\section{Bibliografía}

BESTARD, J. Parentesco y modernidad. Paidós Ibérica. Barcelona, 1998.

GANDÍA BARBER, J.D. El impedimento de consanguinidad. Historia y fundamentación. Ediciones Laborum. España, 2007.

GÓMEZ GARCÍA, Pedro, «Familia y matrimonio sólo existen en la red del parentesco (antropológicamente hablando)", Gazeta de Antropología, [en línea]. 24 (1) (2008). Disponible en: http://hdl.handle.net/10481/7073 [consultado el 12 de diciembre de 2019]

GOODY, J. La evolución de la familia y del matrimonio en Europa. Editorial Herder. Barcelona, 1986, pp. 249 ss.

- La Constitución española de 1978. Anaya. Madrid, 1982.

LORENZO PINAR, F.J. (ED.) La familia en la Historia. Ediciones Universidad de Salamanca. Salamanca, 2009, pp.27-39, 121-134, 135-157.

MOLINIÉ BERTRAND, A., RODRÍGUEZ JIMÉNEZ, P. (eds). A través de los tiempos. Diccionario de fuentes para la Historia de la familia. Colección Mestizo. Universidad de Murcia. Murcia, 2000. Pp. 77-78.

MONTESQUIEU, Charles, Espiritu de las leyes, Madrid, Imprenta de Marcos Buenos, 1845.

NÚNEEZ ROLDÁN, F. En los confines del reino. Huelva y su tierra en el siglo XVIII. Publicaciones de la Universidad de Sevilla. Sevilla, 1987.

- Sagrada Biblia. Editorial Católica. Madrid, 1964. Pp. 126, 144, 145.

SÁNCHEZ LORA, J. L. Demografía y Análisis Histórico. Ayamonte 1600-1860. Excma. Diputación Provincial de Huelva. Huelva, 1987. 
Anexo I. Ficha Empleada a modo de plantilla para eXtraer los Datos más SigniFICATIVOS DE CADA EXPEDIENTE

\begin{tabular}{|c|c|c|c|}
\hline \multicolumn{4}{|c|}{ NÚMERO DE EXPEDIENTE: } \\
\hline \multicolumn{2}{|l|}{ COMIENZA: } & \multicolumn{2}{|l|}{ FINALIZA: } \\
\hline \multicolumn{4}{|c|}{ GRADO DE CONSANGUINIDAD: } \\
\hline \multicolumn{2}{|l|}{$\begin{array}{l}\text { CONTRAYENTE VARÓN. } \\
\text { NOMBRE: } \\
\text { EDAD: } \\
\text { ESTADO CIVIL: } \\
\text { NATURAL DE: } \\
\text { VECINO DE: } \\
\text { PROFESIÓN: } \\
\text { ¿ÁGRAFO?: }\end{array}$} & \multicolumn{2}{|c|}{$\begin{array}{l}\text { CONTRAYENTE MUJER. } \\
\text { NOMBRE: } \\
\text { EDAD: } \\
\text { ESTADO CIVIL: } \\
\text { NATURAL DE: } \\
\text { VECINO DE: } \\
\text { PROFESIÓN: } \\
\text { ¿ÁGRAFO?: }\end{array}$} \\
\hline \multicolumn{4}{|l|}{ MOTIVO DE LA DISPENSA: } \\
\hline $\begin{array}{l}\text { TESTIGO INFORM. GRAL } 1 . \\
\text { NOMBRE: } \\
\text { EDAD: } \\
\text { NATURAL DE: } \\
\text { VECINO DE: } \\
\text { PROFESIÓN: } \\
\text { ¿ÁGRAFO?: }\end{array}$ & \multicolumn{2}{|c|}{$\begin{array}{l}\text { TESTIGO INFORM GRAL } 2 . \\
\text { NOMBRE: } \\
\text { EDAD: } \\
\text { NATURAL DE: } \\
\text { VECINO DE: } \\
\text { PROFESIÓN: } \\
\text { ¿ÁGRAFO?: }\end{array}$} & $\begin{array}{l}\text { TESTIGO INFORM. GRAL } 3 . \\
\text { NOMBRE: } \\
\text { EDAD: } \\
\text { NATURAL DE: } \\
\text { VECINO DE: } \\
\text { PROFESIÓN } \\
\text { ¿ÁGRAFO?: }\end{array}$ \\
\hline \multicolumn{2}{|l|}{$\begin{array}{l}\text { TESTIGOS DE OFICIO } 1 . \\
\text { NOMBRE: } \\
\text { EDAD: } \\
\text { NATURAL DE: } \\
\text { VECINO DE: } \\
\text { PROFESIÓN: } \\
\text { ¿ÁGRAFO?: }\end{array}$} & \multicolumn{2}{|c|}{$\begin{array}{l}\text { TESTIGO DE OFICIO } 2 . \\
\text { EDAD: } \\
\text { ESTADO CIVIL: } \\
\text { NATURAL DE: } \\
\text { VECINO DE: } \\
\text { PROFESIÓN: } \\
\text { ¿ÁGRAFO?: }\end{array}$} \\
\hline \multicolumn{4}{|l|}{ SENTENCIA: } \\
\hline
\end{tabular}


